\title{
An Introduction to Elite Interviewing
}

\section{Philipp Köker}

Cite as: Köker, Philipp. 2016. An Introduction to Elite Interviewing. SAGE Research Methods. http://dx.doi.org/10.4135/9781473968660

Abstract: Dr Philipp Koeker explains how elite interviews differ from other interviews, and he offers suggestions for success. He identifies elite characteristics, access difficulties, power challenges, and reliability.

Keywords: challenging behaviour; consent; elites; flexibility; gratitude; knowledge; memory; motivation; personality; power and power relations; practices, strategies, and tools; preparedness; rapport; recording; representation; roles and responsibilities

\section{Transcript:}

My name is Philipp Köker. I'm a postdoctoral research associate at University College London, School of Slavonic and East European studies. In this tutorial, we are going to talk about what characterizes elites as a respondent group, how to prepare and conduct interviews, and we're going to discuss the issue of reliability and other factors that need to be taken into account.

Elite interviews are very popular research methods. They can help researchers to gain insights and information that would not be available in any other form. They can also help to interpret the personalities behind certain decisions, and thereby provide better explanations of the outcome of events. Elite interviews are therefore used in different projects and in different ways across the social sciences, mostly, but not only, by PhD students and early career researchers. Elites can be loosely defined as those in close proximity to power or as people who hold or have held privileged positions in society. 
Elites can be quite diverse as a respondent group with regards to age, social background, and education. However, they share certain characteristics which set them apart from other interviewees. Elites are in positions of responsibility, and even when they're out of office or retired, still have a busy schedule so that the time for building rapport and asking questions is very limited. Elite respondents are used to being interviewed, which can help the researcher. On the other hand, they also more skilled at deflecting questions and may attempt to take control of the agenda. Elites may also more frequently have an interest in misrepresenting their role in their own favour. Last, elites are more likely than other respondent groups to object to closed questions. They prefer open ended questions, which allow them to elaborate on their answers and their views. As in every research project involving interviews, one needs to think about what exactly interviews are needed for.

Elite interviews are an attractive method because they allow for gaining specialist knowledge that is not otherwise available. Nevertheless, due to the added time and effort that it takes to arrange, conduct, and to analyse elite interviews, including them in your study can be a futile endeavour. Not all interview types are appropriate for elite interviewing, and you need to think about how this relates to your research question. Due to the reluctance of elite respondents to answer closed questions and due to time constraints, a majority studies uses semi-structured interviews. Semi-structured interviews allow for the inclusion of open ended questions, but are also relatively focused and give the researcher more control over the interview vis-à-vis the respondent. As with other interview research, you should also talk to your departmental or university data representative. Interviewing political elites can often be exempt from ethics approval. However, you always need to check with specific reference to your research what approval is needed.

One of the most important points in preparing elite interviews is background research. Only when you're really well prepared can you make sure that you ask relevant questions or challenge elites on what they said in order to ensure response validity. Another key to 
preparation is the development of an interview guide. An interview guide is a set of questions grouped in thematic order that you would like to ask. Quite often it is not possible to create just one interview guide for all of your interviews. For example, in a study on the work of members of parliament, you wouldn't probably have different interview guides for members of parliament, the people who work in the office, and journalists or other experts that you might want to interview.

Of course, all this preparation is futile if you do not get an interview. How to approach a prospective respondent depends very much on the respective interviewee. Nowadays, you can quite often call their office or send an email, but some people still recommend that you send a formal letter requesting an interview. In any case, you need to be aware that most of the time you will not be able to contact elites directly, but you have to go through an additional layer of secretaries or personal assistants. You need to make sure that you convince them and elites that only they can answer your question and that their contribution is needed to successfully complete your research project. As elites are very busy, you might need to plan some time for arranging interviews in advance, particularly if you request more than 30 minutes of their time. However, elites also often have unexpected breaks in their schedule, during which they're willing to fit researchers in, so you need to be flexible. At the beginning of the interview, you will usually explain to respondent once again what your research is about and gain their consent to be interviewed.

Particularly high ranking and foreign elites might be reluctant to sign a participation or consent form, so you should check with your ethics counsel or university data representative whether it is OK to establish consent orally. Before you actually begin to conduct the interview, you need to agree with you respondent on how you're going to record their answers and how you're going to use them. For example, whether you plan to quote them directly or not. Quite often, elites will allow you to tape record interviews, but if you're talking about particularly controversial or sensitive subjects, it might be advisable to take notes by 
hand to increase rapport. When conducting the interview, you should be aware that the power relationship between respondent and interviewer is quite different to non-elite interviews.

In interviews with other respondent groups, it is usually the interviewer who holds more power, because they ask the question and control the flow of the conversation, but in elite interviews, they only in a more powerful position, but they also hold the information that you, the researcher, are after. Here you need to make sure that you're well prepared so that you retain some control over the interview and are not led off topic. Sometimes it can be advisable to politely challenge elites on what they have said to increase response validity, but also to show them that you're well prepared and are challenging their powerful position.

After the interview, you should, of course, thank your respondent and maybe their staff, who helped arrange the interview. You should also send a letter or email thanking them once again for their time. This helps you to keep a foot in the door and maybe come back for another interview or a few follow up questions. When you're thinking about including a literal quote from one of your interviewees in your study, this might sometimes even be necessary. Analyzing interview data is a topic for itself and always depends on your specific project.

However, in elite interviews, you should specifically think about the issue of reliability. Reliability is, of course, an issue in all research, yet in interview research, particularly involving elites, we need to remind ourselves that our respondents are in no way obligated to tell us the truth, and in extreme cases, might even consciously mislead us or misrepresent their role in certain events. Respondents might also not remember events correctly and may fuse them with what they've read or heard from other sources. Interviews and elite interviews in particular should therefore not be used as the only method in any study.

In this tutorial, I've talked about interviewing elites, who are usually defined as people in close proximity to power. While they can be a relatively diverse respondent group, they share certain characteristics that set them apart from other respondents. These 
characteristics need to be taken account at different stages of the research process, not only when preparing and conducting elite interviews, but also when analysing the results. 